
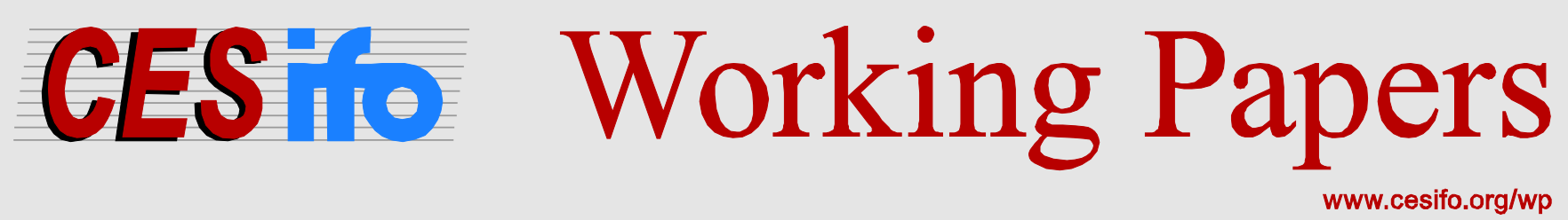

\title{
Health Insurance Coverage and Risky Health Behaviors Among Young Adults
}

\author{
Barış K. Yörük
}

\section{CESIFO WORKING PAPER NO. 5495 \\ CATEgory 2: Public CHOICE \\ August 2015}
An electronic version of the paper may be downloaded
- from the SSRN website: Www.SSRN.com
- from the RePEc website: Www.RePEc.org
- from the CESifo website: www.CESifo-group.org/wp




\title{
Health Insurance Coverage and Risky Health Behaviors Among Young Adults
}

\begin{abstract}
This paper investigates the relationship between health insurance coverage and risky health behaviors among young adults using the confidential version of the National Longitudinal Survey of Youth, 1997 Cohort (NLSY97). Before the Affordable Care Act required all employers to provide health insurance to employees' children until the age of 26 (before September, 2010), many health insurance contracts covered dependents through age 19. Using a regression discontinuity design framework, I find that approximately 6 percent of young adults lose their health insurance coverage once they turn 19. I also find some evidence that the discrete change in health insurance coverage status at age 19 has spillover effects on heavy drinking, especially for males, but does not have any significant impact on smoking or marijuana use habits of young adults. These results are robust under several different parametric and non-parametric models and not sensitive to the selection of samples based on gender.
\end{abstract}

JEL-Code: I120, I130, I180.

Keywords: alcohol consumption, health insurance coverage, marijuana use, smoking.

Barış K. Yörük

Department of Economics

University at Albany, SUNY

1400 Washington Ave

USA - Albany, NY 12222

byoruk@albany.edu

August 18, 2015

This paper uses confidential data provided by Bureau of Labor Statistics (BLS). The views expressed in this paper are those of the author and do not necessarily reflect those of the BLS. 


\section{Introduction}

Although risky decisions made by young adults can have considerable impacts on their immediate health and other social and economic outcomes that may affect their future, little is known about how health insurance coverage affects young adults' attitudes towards risk. Understanding the relationship between health insurance coverage and risky health behaviors is also particularly important in light of the fact that extending dependent coverage to young adults is a major component of the Affordable Care Act (ACA). On the one hand, the existing literature documents that the ACA has significantly increased the number of young adults that are covered by a health insurance plan and that health insurance coverage in early life has positive effects on future health (Antwi, Moriya, and Simon, 2013; Currie, Decker, and Lin, 2008). On the other hand, compared to their peers without health insurance, young adults with health insurance coverage may be more likely to engage in risky behaviors such as excessive drinking, heavy smoking, and illicit drug use since they are less likely to suffer from the potential financial costs of health care. ${ }^{1}$

Before the ACA required all employers to provide health insurance to employees' children until the age of 26 (before September, 2010), many private health insurance contracts covered dependents through age 19 (Anderson, Dobkin, and Gross, 2012; Timmins, 2012). Recently, few studies find that before the introduction of the ACA, health insurance coverage rates among young adults exhibited a discrete change at this cutoff age. In particular, these studies find a 5 to 8 percentage point reduction in the probability of having health insurance coverage at age 19 (Anderson, Dobkin, and Gross, 2012; Cardella and Depew, 2014). They also show that the discrete change in health insurance coverage status at age 19 leads to significant reductions in self-reported health, emergency department visits, and inpatient hospital admissions. This finding is also supported by other recent papers that use randomized controlled trials to assess the effect of health insurance coverage on health care utilization and expenses (Finkelstein, et al., 2012).These findings imply that young adults who lose their health insurance coverage at a certain age may be less likely to engage in risky behaviors to avoid a costly hospital visit or emergency medical care. However, very little is known about the potential impacts of health insurance coverage on risky behaviors among this age group.

Learning more about the potential changes in risky behaviors among young adults due to a change

\footnotetext{
${ }^{1}$ This behavior is akin to ex ante moral hazard as discussed by Ehrlick and Becker (1972).
} 
in health insurance coverage status is quite important since several studies linked risky behaviors to economic and social outcomes such as earnings, educational attainment, criminal behavior, mental health, and future dependence to illicit drugs. ${ }^{2}$ Furthermore, although there exists an extensive literature on the differences in risk taking behaviors of males and females, most of this literature is based on experimental data and to the best of my knowledge, no previous study has investigated whether the effect of a change in health insurance coverage status on risk taking behavior differs by gender using the discrete change in health insurance coverage status at a certain age cut off.

In this paper, I use data from the confidential version of the National Longitudinal Survey of Youth (NLSY97), which contains the exact birth date of the respondents, to investigate the relationship between health insurance coverage status and various risky health behaviors among young adults. The information on the exact birthdays is unique and crucial to identify the treatment and control groups (those who are younger or older than 19). I focus on a wide range of risky behaviors, which may lead to a hospital or emergency department visit such as heavy alcohol consumption, marijuana use, and heavy smoking. The empirical methodology is a regression discontinuity (RD) design, which compares the outcomes of those who are slightly older than 19 (treatment group) with those who are slightly younger than the same age cutoff (control group). Since, we expect that these two groups of young adults, who are around the same age cutoff, have very similar observable and unobservable characteristics, the differences in their attitudes towards risk should be solely due to the differences in their probability of having health insurance at this particular age cutoff. ${ }^{3}$

The results from various RD models show that approximately 6 percent of young adults lose their health insurance coverage once they turn 19. This result is robust under alternative models and is not sensitive to the selection of the sample based on gender. I also find that while the change in health insurance coverage has a very limited and statistically insignificant effect on smoking and marijuana use among young adults, it significantly affects heavy alcohol consumption. In particular, I find that the probability of consuming 5 or more drinks a day decreases by approximately 2 percentage points at age 19. This effect is highly significant and mainly driven by the decrease in alcohol consumption among males.

\footnotetext{
${ }^{2}$ See, for example, Agrawal, et al. (2004), Balsa, Giuliano, French (2011), Ertan Yörük and Yörük (2012), Fergusson and Boden (2008), Keng and Huffman (2010), Hingson, Heeren, and Winter (2006), and Renna (2008).

${ }^{3}$ To the best of my knowledge, there are no other federal or state level policies that are implemented based on the age cutoff of 19 that may also affect health insurance coverage status of young adults.
} 
The rest of this paper is organized as follows: The next section presents a review of the existing literature. Section 3 presents the data. Section 4 provides a brief discussion of the empirical methodology. Section 5 presents the results under alternative model specifications. Section 6 provides a summary of main findings and concludes.

\section{Literature review}

The existing literature on the effects of health insurance coverage mostly focuses on health care utilization and overall health status. For instance, using data from the randomized RAND Health Insurance Experiment, Manning et al. (1987) find that lower co-payments increased doctor visits. Similarly, Miller (2012), Kolstad and Kowalski (2012), and Van der Wees, Zaslavsky, and Ayanian (2013) find that the Massachusetts universal coverage initiative of 2006 increased preventive services while reducing emergency room visits, avoidable hospitalizations, and medical needs unmet. The findings on health insurance's effect on health status is mixed. Brook, et al. (1983) argue that better insurance coverage is associated with improvement in health for only certain groups of people. However, using data from Massachusetts health reform, several others find that health insurance coverage improved self-assessed, overall, physical, and mental health (Courtemanche and Zapata, 2014; Sommers, Long, and Baicker, 2014).

Several recent papers investigate the early effects of the ACA's dependent coverage mandate. Antwi, Moriya, and Simon (2014) find that the ACA's dependent coverage provision increased hospital admissions. On the other hand, Chua and Sommers (2014) find no significant effects of this policy change on alternative measures of hospital, primary care, and prescription drug utilization.

More directly relevant to this paper, using a regression discontinuity (RD) design, few studies investigate the effect of the discrete change in health insurance coverage rates at age 19 on selfreported health status and health care utilization. Using administrative data from six states, Anderson, Dobkin, and Gross (2012) find sizable reductions in emergency department (ED) visits at the age-19 cutoff. Using data from Medical Expenditure Panel Survey (MEPS), Timmins (2012) find that office-based physician visits and prescription drugs are not affected by the change in insurance coverage at age 19, but dental visits are. Moreover, she finds a a small increase in out-of-pocket health expenditures, but no change in health status or ability to afford care at age 19. Using data 
from National Health Interview Survey (NHIS), Cardella and Depew (2014) find that having health insurance coverage significantly increases the likelihood of reporting excellent health among young adults who just turn 19. My paper differs from these studies in several ways. First, in contrast to the survey data that were used in the previous studies and contain information only on the birth month and year of the respondents (the MEPS and NHIS), in this paper, I use the confidential version of the NLSY97, which has information on the exact birth and interview date for each respondent. In a $\mathrm{RD}$ analysis which relies on a discontinuity at a cutoff age, this information is quite important and enables one to clearly identify the treatment and control groups. ${ }^{4}$ Furthermore, instead of focusing self-reported health or health care utilization, in this paper, I investigate the relationship between health insurance coverage and risky health behaviors among young adults.

There is little prior evidence on the effects of health insurance coverage on risky health behaviors. Barbaresco, Courtemanche, and Qi (2015) argue that the potential effects of health insurance coverage on risky health behaviors are ambiguous. Health insurance may improve risky behaviors through direct price effects, worsen them through ex ante moral hazard, or affect them in either direction through income effects. The existing studies on the potential effects of health insurance coverage on risky health behaviors also provide mixed results. Brook et al. (1983) find no evidence that better insurance coverage is associated with smoking. However, Dave and Kaestner (2009) find that Medicare decreased physical activity and increased smoking and drinking. Finkelstein et al. (2012) do not find any significant effects of Medicaid on smoking. Similarly, Courtemanche and Zapata (2014) find that the Massachusetts reform did not have any significant effects on smoking or physical activity. In a recent paper, Barbaresco, Courtemanche, and Qi (2015) investigate the effect of the ACA's dependent coverage mandate on health related outcomes of young adults. Using survey data and difference-in-differences methodology, they find that the mandate increased risky drinking, but did not lead to any significant increases in preventive care use.

\footnotetext{
${ }^{4}$ Suppose that one has information only on the birth month and year of each respondent and the interview date. Then, treatment and control groups cannot be precisely identified. For instance, a respondent who was born on January 1, 1984 and interviewed on January 30, 2003 will be mistakenly placed in the control group (those who are 19 and younger). But, this respondent is actually in the treatment group since she is 29 days older than 19 at the time of the interview. Furthermore, by definition, the RD approach estimates the local treatment effect, which calls for a very detailed information around the age-19 cutoff.
} 


\section{Data}

I use data from the 2002, 2003, and 2004 waves of the confidential version of the NLSY97 for the empirical analysis. ${ }^{5}$ The NLSY97 consists of a nationally representative sample of 9022 youths who were 12 to 16 years old as of December 31, 1996. Round 1 of the survey took place in 1997 . In that round, both the eligible youth and one of that youth's parents received personal interviews. Youths continue to be interviewed on an annual basis. The confidential version of the NLSY97 contains information on respondents' exact date of birth and exact interview date for each survey year. This information is essential to calculate the exact age in days for each respondent at the time of the interview. Therefore, using this information, it is possible to determine the number of days that each respondent is younger or older than 19. I restrict the sample to those respondents who were up to 12 month (360 days) younger or older than this age cutoff. The choice of age bandwidth follows Anderson, Dobkin, and Gross (2012) and Cardella and Depew (2014). However, as a robustness check, I also consider a smaller bandwidths of 9 and 10 months (270 and 300 days). In addition to standard demographic information, the NLSY97 also contains questions about health insurance coverage and various risky behaviors such as heavy alcohol consumption, marijuana use, and smoking habits. The outcome variables are derived from these questions.

In particular, the respondents were asked whether they have any kind of health care coverage, including health insurance, prepaid plans such as HMOs, or government plans such as Medicare. As indicators of risky behavior, I use information on alcohol consumption, smoking, and marijuana use in the NLSY97. In contrast to similar surveys of its kind, in the NLSY97, information on these variables refers to the past month. ${ }^{6}$ This relatively short reference period is desirable since my empirical strategy compares those who are slightly older than 19 with those who are slightly younger than this cutoff age and yields estimates of local treatment effect. In general, I consider six outcomes related to alcohol consumption. Three of these outcomes are indicators of heavy drinking participation: whether the respondent engaged in binge drinking (consumed five or more drinks on the same occasion) in

\footnotetext{
${ }^{5}$ The respondents of the NLSY97 were asked about their health insurance coverage starting from the 2002 wave. Due to the longitudinal nature of the NLSY97, the respondents get older over time and all the respondents are 20 years old or older after the 2004 wave. Since the RD analysis in this paper uses data for those who are at most one year younger or older than the cutoff age of 19, the sample is restricted to the 2002, 2003, and 2004 waves of the NLSY97.

${ }^{6}$ For instance, in National Health Interview Survey (NHIS), questions on alcohol consumption typically refer to the prior 12 months with an option to report alcohol consumption over the past year, the past month, or the past week.
} 
the past month, engaged in heavy drinking (engaged in binge drinking at least five times) in the past month, and on average consumed at least five drinks (binge drinking) every day during the past month. $^{7}$ Two of the remaining alcohol consumption related outcomes measure the number of days that the respondent had at least one drink and the number of days that she had five or more drinks on the same occasion during the past month. Finally, the remaining outcome measure the intensity of drinking as the average number of drinks that she had per day during a one month period. ${ }^{8}$

In order to test the effect of the change in insurance coverage status on smoking behavior, I consider four different indicators of smoking. These variables are whether the respondent engaged in heavy smoking (smoked 20 cigarettes or more a day) at least once over the past month, number of days that she smoked during the past month, number of days that she engaged in heavy smoking, and the average number of cigarettes that she smoked per day over the past month. ${ }^{9}$ Finally, to investigate the relationship between health insurance coverage and marijuana use among young adults, I use three different indicators of marijuana use. These variables are whether the respondent used marijuana over the past month, number of days that she used marijuana over the past month, a binary indicator of heavy marijuana use (whether she used marijuana at least 10 days during the past month).

Appendix A presents the description of the outcome variables and their summary statistics. The summary statistics for the variables used in the empirical analysis are comparable to other sources of survey data on health insurance coverage and risky behavior among of young adults such as the NHIS and National Survey of Drug Use and Health (NSDUH). Furthermore, Table 1 provides similar statistics for treatment (those who are older than 19) and control (those who are younger than 19) groups. These raw numbers suggest that although these two distinct group of young adults are comparable alcohol consumption, smoking, and marijuana use habits, those who are younger than 19

\footnotetext{
${ }^{7}$ I do not observe these binary variables directly. The respondents were asked the following questions: "During the last 30 days, on how many days did you have one or more drinks of an alcoholic beverage?" and "On how many days did you have five or more drinks on the same occasion during the past 30 days? By occasion we mean at the same time or within hours of each other". The alcohol participation variables for the corresponding questions are coded unity if the respondent reported consuming alcohol on at least one day during the past month and zero otherwise.

${ }^{8}$ The respondents were asked the following question: "In the past 30 days, on the days you drank alcohol, about how many drinks did you usually have?" In order to calculate the average number of drinks per day during a one month period, I multiply the number of days that the respondent drank alcohol with the average number of drinks that she had on those days and divide the result by 30 .

${ }^{9}$ The respondents were asked the following question: "When you smoked a cigarette during the past 30 days, how many cigarettes did you usually smoke each day?" In order to calculate the average number of cigarettes that the respondent smoked per day over the past month, I multiply the number of days that the respondent smoked over the past month with the number of cigarettes that she smoked on those days and divide the result by 30 .
} 
are more likely to have health insurance.

\section{Methodology}

I use a RD design to estimate the discrete change in the probability of having health insurance coverage and self-reported risky health behaviors at age 19 (Imbens and Lemieux, 2008 and Lee and Lemieux, 2009). The RD approach compares outcomes across youths with similar income, marital status, educational attainment, and other observable individual characteristics, but with different probabilities of health insurance coverage. The main identifying assumption is that the observed and unobserved determinants of health insurance coverage status are likely to be distributed smoothly across the age-19 cutoff. Therefore, the changes in risky health behaviors such as heavy alcohol consumption, smoking, and marijuana use at this age can solely be attributed to the potential change in health insurance coverage. ${ }^{10}$ Following the previous literature, I estimate a parametric and a nonparametric local linear spline regression that allows the slope to vary from right and left of the age-19 threshold. The main parametric RD model used in the empirical analysis is as follows:

$$
Y_{i}=\beta^{\prime} X_{i}+\gamma T_{i}+\alpha A g e_{i}+\lambda\left(T_{i} \times A g e_{i}\right)+\varepsilon_{i}
$$

where $Y_{i}$ represents a particular outcome for individual $i$ and $\varepsilon_{i}$ is the error term. The set of observable characteristics for individual $i$ are denoted by $X_{i}$ and includes family size, dummy variables controlling for household income, gender, race, educational attainment, and marital and employment status of the respondent, and a dummy variable which is equal to unity if the respondent is a student. ${ }^{11}$ The treatment variable is denoted by $T_{i}$ and takes the value of unity if the respondent's age is greater than 19 as of the interview date. A smooth function of age profile, which is also known as the forcing variable in the context of a RD design is denoted by $A g e_{i}$. Since, I observe the exact birth and interview date for each respondent, I was able to calculate the day difference between the interview date and the $19^{\text {th }}$ birthday. Therefore, for each respondent, the variable $A g e_{i}$ denotes the number of days before or after the $19^{\text {th }}$ birthday. The coefficient $\gamma$, the main coefficient of interest, indicates the change in the outcome variable at the cutoff age of 19. Following the common practice in the literature, for all models, I report the standard errors that are clustered by the forcing variable $\left(A g e_{i}\right)$.

\footnotetext{
${ }^{10}$ This is a partly testable assumption. I present the relevant results in the next section.

${ }^{11}$ Since several observations are missing for household income and employment status, I use dummy variables controlling for the "missing" observations for these set of covariates.
} 
For non-parametric models, following Hahn, Todd, and van der Klaauw (2001) and Porter(2003), I use local linear regressions to estimate the left and right limits of discontinuity at age 19. The difference between the two limits is interpreted as the local treatment effect of the change in the probability of having health insurance coverage at the cutoff age on outcome variables. Following Malamud and Pop-Eleches (2011), I estimate this in one step using triangular kernel which has been shown to be boundary optimal by putting more weight on observations closer to the cutoff point (Cheng, Fan, Marron, 1997). ${ }^{12}$ The remaining estimation issue for the non-parametric models is the selection of appropriate bandwidth. Since the RD is identified only at the discontinuity, one needs to try to balance the goals of staying as local to the cutoff point at age 19 as possible while ensuring that there are enough data to yield informative estimates. In all non-parametric models, I use the bandwidth selection procedure that is proposed in a recent paper by Imbens and Kalyanaraman (2012).

\section{Results}

The underlying assumption for the RD analysis in this context is that except for the probability of health insurance coverage and related risky behaviors, other observable and unobservable characteristics of young adults should not exhibit a discrete change at their $19^{\text {th }}$ birthday. This is a partially testable assumption. Estimating equation (1) separately for all control variables, I find that for each covariate, the coefficient of the treatment variable is insignificant and hence, there is no evidence of statistically significant discontinuity in any of the control variables at the cutoff age. Table 2 shows this result. Furthermore, in order to further illustrate this result, I plot the estimates from the parametric regressions and present the results for selected control variable in Figure 1. The linear prediction of each control variable appears to fit the actual data well and exhibits either no or an insignificant small change at age 19. As an additional robustness check, for all outcome variables, I report results from the models that are estimated with an without control variables. As expected, the results from these models are quite similar. This implies that control variables do not exhibit a discrete change at age 19 and therefore, have very limited impact on the estimates of the discontinuity

\footnotetext{
${ }^{12}$ Lee and Lemuiex (2009) argue that an alternative way of putting more weight on observations close to the cutoff is to re-estimate a non-parametric model with a rectangular kernel using smaller bandwidths. Following, Lee and Lemuiex (2009), I also estimate our non-parametric models using rectangular kernel and smaller bandwidths. However, as in previous studies, the choice of kernel has little effect on my estimates (Fan and Gijbels, 1996).
} 
at this age.

Another potential problem that may affect the estimates of the RD analysis is non-random assignment of the forcing variable. If there is a discontinuous change in the number of observations at the cutoff age of 19, this may bias the estimates from the empirical models. In Appendix B, I plot the number of observations for each 30-day block for one year before and after the cutoff age of 19 . Number of observations for the month just before the $19^{t h}$ birthday is quite similar to the number of observations for the month just after the $19^{\text {th }}$ birthday. Furthermore, I also conduct the density test proposed by McCrary (2008) and find no evidence of discontinuity in the density of the running variable at the cutoff point (density estimate is -0.058 with a standard error of 0.123 ).

\subsection{Insurance coverage}

Table 3 presents the estimation results from the RD analysis of the discontinuity in health insurance coverage status at age 19. The results show that 5.2 to 6.3 percent of young adults lose their health insurance coverage once they turn 19. These estimates are similar to Anderson, Dobkin, Gross (2012) and Cardella and Depew (2014). When I estimate similar models for males and females, a similar result prevails. Approximately 6 percent of male young adults lose their coverage at age 19, whereas 5.3 to 7 percent of females lose their health insurance coverage at the same age cutoff. Figure 2 further illustrates this result for the full sample and separately for males and females. Furthermore, Table 4 shows that the estimates of the discontinuity are robust to the selection of smaller age bandwidths of 270,300 , and 330 days. These alternative specifications imply that 4.8 to 6.5 percent of young adults lose their health insurance coverage at age 19. These estimates remain statistically significant at conventional significance levels.

\subsection{Alcohol consumption}

In Table 5, I present the estimated impact of losing health insurance coverage at age 19 on various indicators of alcohol consumption among young adults. For the full sample, although the results imply that young adults tend to decrease their average alcohol consumption and the number of days that they consume alcohol when they lose their health insurance coverage, neither of these estimates are statistically significant. Similarly, the effect of the discontinuity at age 19 on binge drinking outcomes is relatively small and statistically insignificant. Table 5 also shows that when separate 
models for males and females are estimated for the same outcomes, the estimates remain similar and statistically insignificant. However, the results suggest that very heavy drinkers (those who consume at least 5 drinks everyday) become less likely to engage in heavy drinking once they turn 19. Under alternative specifications, I find that the probability of consuming 5 or more drinks a day decreases by approximately 2 percentage points. This effect is highly significant and mainly driven by the change in alcohol consumption behavior of males. In particular, the probability of consuming 5 or more drinks a day decreases by approximately 4 to 5 percentage points for males. However, for females, the effect of losing health insurance coverage at age 19 on this particular outcome is very small and statistically insignificant. Figure 3 further illustrates these results. While the probability of consuming 5 or more drinks a day exhibits a sharp decrease at the $19^{\text {th }}$ birthday, the change in other alcohol consumption outcomes at this age is limited and statistically insignificant.

Using the estimates of the discontinuity at age 19, it is also possible to estimate the direct impact of the health insurance coverage status on heavy drinking. Following Timmins (2012) and Cardella and Depew (2014), this method relies on using the discrete change in the probability of having health insurance coverage at age 19 as an instrument for the health insurance coverage status in the first stage. The main assumption in this instrumental variable (IV) method is that the probability of having health insurance changes significantly at age 19 but at this cutoff age, unobserved determinants of risky behaviors are not affected. In this context, the IV estimate is actually the ratio of the discontinuity in the probability of having a particular risky health behavior at age 19 to the discontinuity in the probability of having health insurance at the same age cutoff. ${ }^{13}$ In parametric models that contain full set of control variables, I found that for the full sample, 5.6 percent of young adults lose their insurance coverage at age 19. At this age, the probability of consuming on average 5 or more drinks per day decreases by 1.9 percentage points. Therefore, the probability of consuming on average 5 or more drinks per day would increase by 0.34 percentage points as a response to a 1 percentage points in the probability of having health insurance coverage $(1.9 / 5.6=0.34)$.

\subsection{Smoking behavior}

Table 6 reports the estimation results from the RD analysis of the change in smoking behavior among young adults at age 19. Although losing health insurance coverage at age 19 appears to increase

\footnotetext{
${ }^{13}$ Timmins (2012) provides a simple explanation of this relationship.
} 
the number of days that young adults smoked cigarettes during the past month, this effect is not statistically significant. The effect of a change in health insurance coverage status at age 19 cutoff is more pronounced for heavy smoking, especially for males. On average, males tend to reduce the average number of cigarettes that they smoked per day by 0.4 and the number of days that they engaged in heavy smoking by 0.35 . However, none of these estimates are statistically significant. Figure 4 also shows that smoking outcomes are smoothly distributed around age 19 and do not exhibit a discrete change at the cutoff point.

\subsection{Marijuana use}

The results reported in Table 7 show that the effect of losing health insurance coverage at age 19 on marijuana use among young adults is relatively small. In particular, results for the full sample suggest that the probability of engaging heavy marijuana use increases by 1 to 1.5 percentage points. Compared with females, males are less likely to engage in heavy marijuana use upon turning 19. Similarly, females tend to increase the number of days that they used marijuana by 0.34 , whereas for males this effect is almost null. However, similar to smoking outcomes, the effect of losing health insurance coverage at age 19 on marijuana use among young adults is not significant at conventional significance levels. Figure 5 illustrates these findings and show that marijuana use among young adults is not significantly affected by the change in insurance coverage status at age 19 .

\section{Conclusion}

In this paper, I investigate the relationship between health insurance coverage and risky health behaviors among young adults using the confidential version of the NLSY97 which contains information on the exact birth date of the respondents. This information is unique and enables one to clearly identify the treatment and control groups. The identification strategy relies on the fact that before the introduction of the ACA, many health insurance contracts covered dependents through age 19. This generates a discrete change in the probability of having a health insurance policy at this cutoff age. In particular, using a RD design, I find that 5.2 to 6.3 percent of young adults lose their health insurance coverage once they turn 19. This result is robust to the selection of alternative bandwidths, model specifications, or samples based on gender. 
My findings also suggest that while the discrete change in health insurance coverage status has a very limited and statistically insignificant effect on smoking and marijuana use among young adults, it significantly affects heavy alcohol consumption. In particular, I find that the probability of consuming 5 or more drinks a day decreases by approximately 2 percentage points at age 19 . This effect is mainly driven by the decrease in alcohol consumption among males at this cut off age.

The findings of this paper are not surprising since risk taking behavior of those with relatively low risk of having health problems (18 to 20 year olds) is not likely to change in the short run. The results of this paper are also comparable to those of Brook et al. (1983), Finkelstein et al. (2012), Courtemanche and Zapata (2014), and Barbaresco, Courtemanche, and Qi (2015), who argue that risky health behaviors among young adults might be relatively difficult to improve through access to health care since they require significant life style changes.

Although the findings of this paper have important policy implications, they should also be interpreted with caution. By definition, the RD approach used in this paper identifies the local treatment effect. Therefore, it has a very good internal but limited external validity. The results hold for those who are around the age 19 cutoff, but cannot be generalized to whole population of young adults. Therefore, further research is needed to investigate the effects of health insurance coverage on risky health behaviors among young adults.

\section{References}

[1] Agrawal, A, M.C. Neale, C.A. Prescott, K.S. Kendler, 2004, A twin study of early cannabis use and subsequent use and abuse/dependence of other illicit drugs, Psychological Medicine, 34, $1227-1237$.

[2] Anderson, M., C. Dobkin, and T. Gross, 2012, The effect of health insurance coverage on the use of medical services, American Economic Journal: Economic Policy, 4, 1-27.

[3] Antwi, Y.A., A. Moriya, and K. Simon, 2013, Effects of federal policy to insure young adults: Evidence from the 2010 Affordable Care Act's dependent-coverage mandate, American Economic Journal: Economic Policy, 5, 1-28. 
[4] Antwi, Y.A., A. Moriya, and K. Simon, 2014, Access to Health Insurance and the Use of Inpatient Medical Care: Evidence from the Affordable Care Act Young Adult Mandate, NBER Working Paper No. 20202.

[5] Balsa, A.I., L.M. Giuliano, and M.T. French, 2011, The effects of alcohol use on academic achievement in high school, Economics of Education Review, 30, 1-15.

[6] Barbaresco, S., C.J. Courtemanche, and Y. Qi, 2015, Impacts of the Affordable Care Act dependent coverage provision on health-related outcomes of young adults, Journal of Health Economics, 40, 54-68.

[7] Brook, R.H., et al., 1983, Does free care improve adults' health? Results from a randomized controlled trial, New England Journal of Medicine, 309, 1426-1434.

[8] Cardella, E. and B. Depew, 2014, The effect of health insurance coverage on the reported health of young adults, Economics Letters, 124, 406-410.

[9] Cheng, M.Y., J. Fan, and J.S. Marron, 1997, On automatic boundary correction, Annals of Statistics, 25, 1691-1708.

[10] Chua, K.P., B.D. Sommers, 2014, Changes in health and medical spending among young adults under health reform, Journal of the American Medical Association, 311, 2437-2439.

[11] Courtemanche, C., D. Zapata, 2014, Does universal coverage improve health? The Massachusetts experience, Journal of Policy Analysis and Management, 33, 36-69.

[12] Currie, J., S. Decker, and W. Lin, 2008, Has public health insurance for older children reduced disparities in access to care and health outcomes?, Journal of Health Economics, 27, 1567-1581.

[13] Dave, D., R. Kaestner, 2009, Health insurance and ex ante moral hazard: Evidence from Medicare, International Journal of Health Care Finance and Economics, 9, 367-390.

[14] Ehrlick, I. and G.S. Becker, 1972. Market insurance, self-insurance, and self-protection, Journal of Political Economy, 80, 623-648. 
[15] Ertan Yörük, C. and B.K. Yörük, 2012, The impact of drinking on psychological well-being: Evidence from minimum drinking age laws in the United States, Social Science and Medicine, $75,1844-1854$.

[16] Fan, J., Gijbels, I., 1996, Local Polynomial Modelling and Its Applications. Chapman and Hall, London, UK.

[17] Fergusson, D.M., J.M. Boden, 2008, Cannabis use and later life outcomes, Addiction, 103, 969976.

[18] Finkelstein, E. et al., 2012, The Oregon Health insurance experiment: Evidence from the first year, Quarterly Journal of Economics, 127, 1057-1106.

[19] Hahn, J., P. Todd, and W. van der Klaauw, 2001, Identification and estimation of treatment effects with a regression-discontinuity design, Econometrica, 69, 201-209.

[20] Hingson, R.W., T. Heeren, and M.R. Winter, 2006, Age at drinking onset and alcohol dependence: Age at onset, duration, and severity, Pediatrics, 160, 739-746.

[21] Imbens, G. and T. Lemieux, 2008, Regression discontinuity designs: A guide to practice, Journal of Econometrics, 142, 615-635.

[22] Imbens, G. and K. Kalyanaraman, 2012, Optimal bandwidth choice for the regression discontinuity estimator, Review of Economics and Studies, 79, 933-959.

[23] Keng, S. and W.E. Huffman, 2010, Binge drinking and labor market success: a longitudinal study on young people, Journal of Population Economics, 23, 303-322.

[24] Kolstad, J.T. and A.E. Kowalski, 2012, The impact of health care reform on hospital and preventive care evidence from Massachusetts, Journal of Public Economics, 96, 909-929.

[25] Lee, D.S. and T. Lemieux, 2009, Regression discontinuity designs in economics, NBER Working Paper No. 02138.

[26] Malamud, O. and C. Pop-Eleches, 2011, Home computer use and the development of human capital, Quarterly Journal of Economics, 126, 987-1027. 
[27] Manning, W.G., et al., 1987, Health insurance and the demand for medical care: evidence from a randomized experiment, American Economic Review, 77, 251-277.

[28] Miller, S., 2012, The impact of the Massachusetts health care reform on health care use among children, American Economic Review: Papers and Proceedings, 102, 502-507.

[29] McCrary, J., 2008, Manipulation of the running variable in the regression discontinuity design: A density test, Journal of Econometrics, 142, 698-714.

[30] Porter, J., 2003, Estimation in the regression discontinuity model, Unpublished Manuscript, Harvard University, Department of Economics.

[31] Renna, F., 2008, Alcohol abuse, alcoholism, and labor market outcomes: Looking for the missing link, Industrial and Labor Relations Review, 62, 92-103.

[32] Sommers, B.D., S.K. Long, and K. Baicker, 2014, Changes in mortality after Massachusetts health care reform: a quasi-experimental study, Annals of Internal Medicine, 160, 585-593.

[33] Timmins, L., 2012, How much does health insurance matter for young adults?: Its role on primary medical care consumption, Unpublished Manuscript, Department of Economics, University of British Columbia.

[34] Van der Wees, P.J., A.M. Zaslavsky, and J.Z. Ayanian, 2013, Improvements in health status after Massachusetts health care reform, Milbank Quarterly, 91, 663-689. 
Table 1. Summary statistics for treatment and control groups

\begin{tabular}{|c|c|c|c|c|c|c|}
\hline & \multicolumn{3}{|c|}{ Treatment } & \multicolumn{3}{|c|}{ Control } \\
\hline & No. of obs. & Mean & S.D. & No. of obs. & Mean & S.D. \\
\hline Insurance & 3105 & 0.724 & 0.447 & 1714 & 0.831 & 0.375 \\
\hline Average alcohol consumption & 3093 & 0.683 & 1.650 & 1720 & 0.634 & 1.657 \\
\hline Days of alcohol consumption & 3121 & 3.447 & 5.495 & 1734 & 3.024 & 5.226 \\
\hline Engaged in binge drinking & 3118 & 0.341 & 0.474 & 1734 & 0.302 & 0.459 \\
\hline Days of binge drinking & 3118 & 1.691 & 3.907 & 1734 & 1.472 & 3.599 \\
\hline Engaged in heavy drinking & 3118 & 0.124 & 0.330 & 1734 & 0.109 & 0.311 \\
\hline Consumed 5 or more drinks on average & 3093 & 0.026 & 0.159 & 1720 & 0.029 & 0.168 \\
\hline Used marijuana & 3117 & 0.210 & 0.407 & 1734 & 0.217 & 0.412 \\
\hline Days of marijuana use & 3117 & 2.643 & 7.277 & 1734 & 2.529 & 7.104 \\
\hline Used marijuana more than 10 days & 3117 & 0.105 & 0.307 & 1734 & 0.096 & 0.295 \\
\hline Days of smoking & 3124 & 8.182 & 12.567 & 1735 & 7.691 & 12.311 \\
\hline Engaged in heavy smoking & 3122 & 0.056 & 0.231 & 1735 & 0.054 & 0.226 \\
\hline Avg. no. of cigarettes smoked & 3122 & 3.134 & 7.013 & 1735 & 2.940 & 7.006 \\
\hline Days of heavy smoking & 3124 & 1.735 & 6.965 & 1735 & 1.678 & 6.872 \\
\hline
\end{tabular}

Notes: Sample weighted means are reported. S.D.: standard deviation. 
Table 2. Test of discontinuity in control variables at the $19^{\text {th }}$ birthday

\begin{tabular}{lccccccccccc}
\hline & Log(income) & Married & Female & Family size & Student & GED & High school & Associate & Black & Hispanic & Employed \\
\hline Parametric & -0.054 & -0.002 & 0.028 & -0.001 & 0.029 & -0.006 & -0.041 & 0.001 & -0.005 & 0.021 & -0.001 \\
& $(0.160)$ & $(0.009)$ & $(0.029)$ & $(0.098)$ & $(0.029)$ & $(0.012)$ & $(0.028)$ & $(0.001)$ & $(0.024)$ & $(0.022)$ & $(0.030)$ \\
\multirow{2}{*}{ Non-parametric } & -0.068 & -0.001 & 0.028 & -0.029 & 0.006 & -0.000 & -0.014 & 0.001 & -0.006 & 0.035 & -0.020 \\
& $(0.166)$ & $(0.011)$ & $(0.031)$ & $(0.111)$ & $(0.031)$ & $(0.013)$ & $(0.029)$ & $(0.001)$ & $(0.027)$ & $(0.023)$ & $(0.034)$ \\
No of. Obs. & 3327 & 4851 & 4851 & 4851 & 4797 & 4837 & 4837 & 4837 & 4851 & 4851 & 4851 \\
\hline
\end{tabular}

Notes: An age bandwidth of 360 days on both sides of the cutoff point of the $19^{\text {th }}$ birthday is used in all models. Standard errors are clustered by the forcing variable and reported in parenthesis. 
Table 3. The discontinuity in health insurance coverage at the $19^{\text {th }}$ birthday

\begin{tabular}{|c|c|c|c|c|c|c|}
\hline & \multicolumn{2}{|c|}{ Full sample } & \multicolumn{2}{|c|}{ Male } & \multicolumn{2}{|c|}{ Female } \\
\hline & (1) & $(2)$ & $(3)$ & $(4)$ & $(5)$ & $(6)$ \\
\hline Parametric & $\begin{array}{c}-0.063^{* * *} \\
(0.023)\end{array}$ & $\begin{array}{c}-0.056^{* *} \\
(0.022)\end{array}$ & $\begin{array}{c}-0.058^{*} \\
(0.035)\end{array}$ & $\begin{array}{c}-0.062^{*} \\
(0.033)\end{array}$ & $\begin{array}{c}-0.070^{* *} \\
(0.031)\end{array}$ & $\begin{array}{c}-0.053^{*} \\
(0.030)\end{array}$ \\
\hline Non-parametric & $\begin{array}{c}-0.052^{* *} \\
(0.026)\end{array}$ & & $\begin{array}{c}-0.047 \\
(0.038)\end{array}$ & & $\begin{array}{l}-0.058^{*} \\
(0.035)\end{array}$ & \\
\hline No of. Obs. & 4797 & 4731 & 2437 & 2398 & 2360 & 2333 \\
\hline Controls & $\mathrm{No}$ & Yes & $\mathrm{No}$ & Yes & $\mathrm{No}$ & Yes \\
\hline
\end{tabular}

Notes: An age bandwidth of 360 days on both sides of the cutoff point of the $19^{\text {th }}$ birthday is used in all models. Standard errors are clustered by the forcing variable and reported in parenthesis. The signs ${ }^{*},{ }^{*}$, and ${ }^{* * *}$ denote statistical significance at 10,5 , and 1 percent, respectively. 
Table 4. The discontinuity in health insurance coverage at the $19^{\text {th }}$ birthday for the full sample: Alternative age bandwidths

\begin{tabular}{|c|c|c|c|c|c|c|}
\hline & \multicolumn{2}{|c|}{$\mathrm{BW}=330$ days } & \multicolumn{2}{|c|}{$\mathrm{BW}=300$ days } & \multicolumn{2}{|c|}{$\mathrm{BW}=270$ days } \\
\hline & $(1)$ & $(2)$ & $(3)$ & $(4)$ & $(5)$ & $(6)$ \\
\hline Parametric & $\begin{array}{c}-0.059 * * \\
(0.024)\end{array}$ & $\begin{array}{c}-0.051^{* *} \\
(0.023)\end{array}$ & $\begin{array}{c}-0.065^{* *} \\
(0.026)\end{array}$ & $\begin{array}{c}-0.057^{* *} \\
(0.025)\end{array}$ & $\begin{array}{c}-0.058^{* *} \\
(0.027)\end{array}$ & $\begin{array}{l}-0.048^{*} \\
(0.026)\end{array}$ \\
\hline Non-parametric & $\begin{array}{c}-0.050^{*} \\
(0.027)\end{array}$ & & $\begin{array}{c}-0.046 \\
(0.029)\end{array}$ & & $\begin{array}{c}-0.043 \\
(0.030)\end{array}$ & \\
\hline No of. Obs. & 4437 & 4380 & 3964 & 3913 & 3555 & 3509 \\
\hline Controls & No & Yes & No & Yes & $\mathrm{No}$ & Yes \\
\hline
\end{tabular}

Notes: An age bandwidth of 330,300 , or 270 days on both sides of the cutoff point of the $19^{\text {th }}$ birthday is used for alternative models. Standard errors are clustered by the forcing variable and reported in parenthesis. The signs $*$ and ${ }^{* *}$ denote statistical significance at 10 and 5 percent, respectively. 
Table 5. The discontinuity in alcohol consumption at the $19^{\text {th }}$ birthday

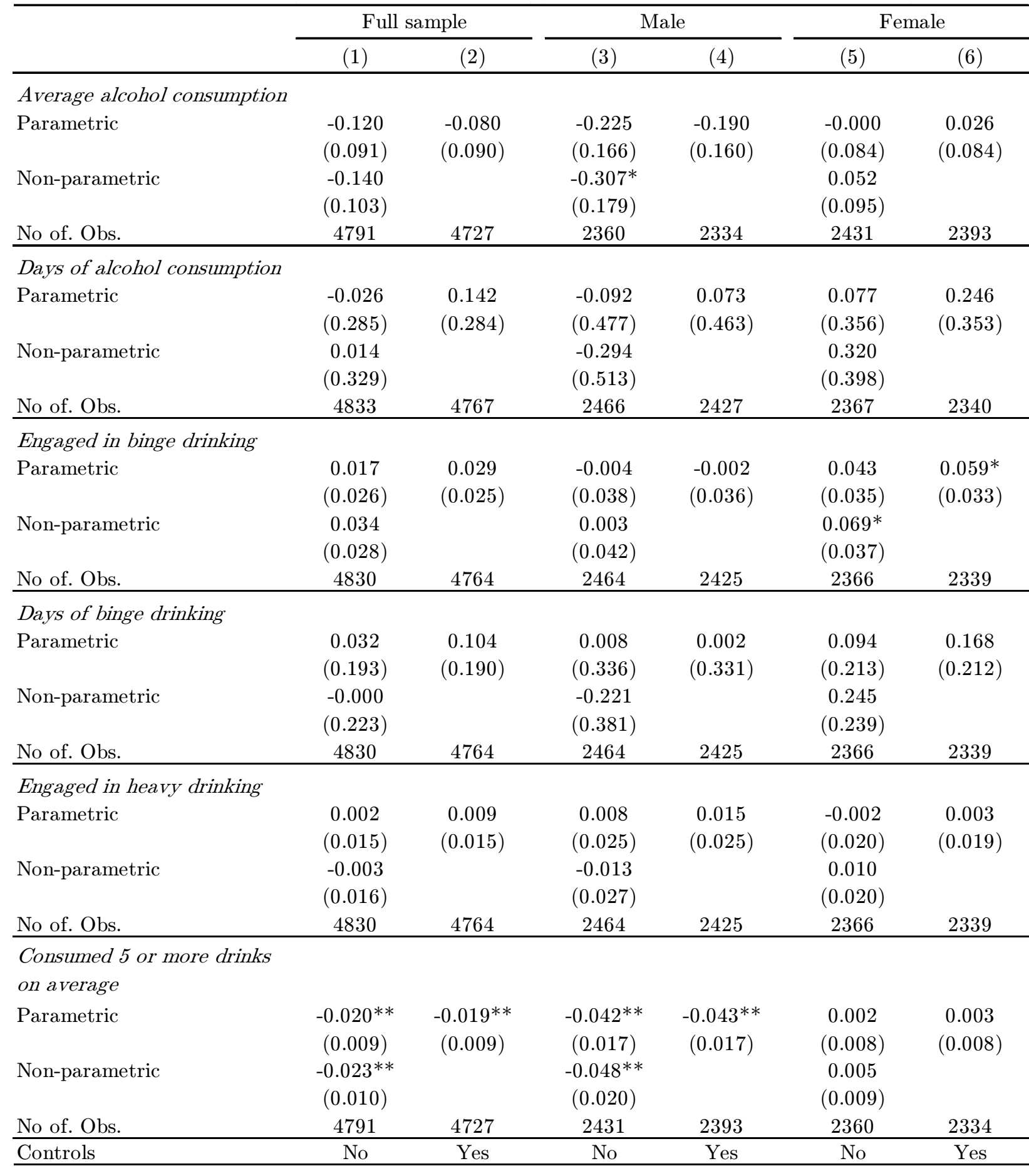

Notes: An age bandwidth of 360 days on both sides of the cutoff point of the $19^{\text {th }}$ birthday is used in all models. Standard errors are clustered by the forcing variable and reported in parenthesis. The signs * and ** denote statistical significance at 10 and 5 percent, respectively. 
Table 6 . The discontinuity in smoking behavior at the $19^{\text {th }}$ birthday

\begin{tabular}{|c|c|c|c|c|c|c|}
\hline & \multicolumn{2}{|c|}{ Full sample } & \multicolumn{2}{|c|}{ Male } & \multicolumn{2}{|c|}{ Female } \\
\hline & $(1)$ & $(2)$ & $(3)$ & $(4)$ & $(5)$ & $(6)$ \\
\hline \multicolumn{7}{|l|}{ Days of smoking } \\
\hline Parametric & $\begin{array}{c}0.393 \\
(0.682)\end{array}$ & $\begin{array}{c}0.318 \\
(0.598)\end{array}$ & $\begin{array}{c}0.360 \\
(1.002)\end{array}$ & $\begin{array}{c}0.501 \\
(0.921)\end{array}$ & $\begin{array}{c}0.482 \\
(0.916)\end{array}$ & $\begin{array}{c}0.211 \\
(0.810)\end{array}$ \\
\hline Non-parametric & $\begin{array}{c}0.364 \\
(0.731)\end{array}$ & & $\begin{array}{c}0.731 \\
(1.078)\end{array}$ & & $\begin{array}{c}0.094 \\
(0.971)\end{array}$ & \\
\hline No of. Obs. & 4837 & 4771 & 2469 & 2430 & 2368 & 2341 \\
\hline \multicolumn{7}{|c|}{ Engaged in heavy smoking } \\
\hline Parametric & $\begin{array}{c}-0.003 \\
(0.012)\end{array}$ & $\begin{array}{c}-0.002 \\
(0.012)\end{array}$ & $\begin{array}{c}-0.011 \\
(0.019)\end{array}$ & $\begin{array}{c}-0.011 \\
(0.018)\end{array}$ & $\begin{array}{c}0.006 \\
(0.016)\end{array}$ & $\begin{array}{c}0.008 \\
(0.016)\end{array}$ \\
\hline Non-parametric & $\begin{array}{c}0.002 \\
(0.013)\end{array}$ & & $\begin{array}{c}0.003 \\
(0.021)\end{array}$ & & $\begin{array}{c}-0.002 \\
(0.018)\end{array}$ & \\
\hline No of. Obs. & 4835 & 4769 & 2468 & 2429 & 2367 & 2340 \\
\hline \multicolumn{7}{|c|}{ Avg. no. of cigarettes smoked } \\
\hline Parametric & $\begin{array}{l}-0.048 \\
(0.402)\end{array}$ & $\begin{array}{l}-0.088 \\
(0.359)\end{array}$ & $\begin{array}{l}-0.400 \\
(0.573)\end{array}$ & $\begin{array}{l}-0.405 \\
(0.514)\end{array}$ & $\begin{array}{c}0.320 \\
(0.497)\end{array}$ & $\begin{array}{c}0.221 \\
(0.458)\end{array}$ \\
\hline Non-parametric & $\begin{array}{l}-0.056 \\
(0.421)\end{array}$ & & $\begin{array}{l}-0.158 \\
(0.642)\end{array}$ & & $\begin{array}{c}0.040 \\
(0.560)\end{array}$ & \\
\hline No of. Obs. & 4835 & 4769 & 2468 & 2429 & 2367 & 2340 \\
\hline \multicolumn{7}{|c|}{ Days of heavy smoking } \\
\hline Parametric & $\begin{array}{l}-0.120 \\
(0.388)\end{array}$ & $\begin{array}{c}-0.100 \\
(0.368)\end{array}$ & $\begin{array}{l}-0.353 \\
(0.574)\end{array}$ & $\begin{array}{c}-0.352 \\
(0.539)\end{array}$ & $\begin{array}{c}0.125 \\
(0.486)\end{array}$ & $\begin{array}{c}0.173 \\
(0.474)\end{array}$ \\
\hline Non-parametric & $\begin{array}{l}-0.038 \\
(0.409)\end{array}$ & & $\begin{array}{c}0.078 \\
(0.623)\end{array}$ & & $\begin{array}{l}-0.084 \\
(0.530)\end{array}$ & \\
\hline No of. Obs. & 4837 & 4771 & 2469 & 2430 & 2368 & 2341 \\
\hline Controls & No & Yes & No & Yes & No & Yes \\
\hline
\end{tabular}

Notes: An age bandwidth of 360 days on both sides of the cutoff point of the $19^{\text {th }}$ birthday is used in all models. Standard errors are clustered by the forcing variable and reported in parenthesis. 
Table 7. The discontinuity in marijuana use at the $19^{\text {th }}$ birthday

\begin{tabular}{|c|c|c|c|c|c|c|}
\hline & \multicolumn{2}{|c|}{ Full sample } & \multicolumn{2}{|c|}{ Male } & \multicolumn{2}{|c|}{ Female } \\
\hline & $(1)$ & $(2)$ & $(3)$ & $(4)$ & $(5)$ & $(6)$ \\
\hline \multicolumn{7}{|l|}{ Used marijuana } \\
\hline Parametric & $\begin{array}{c}0.006 \\
(0.022)\end{array}$ & $\begin{array}{c}0.009 \\
(0.022)\end{array}$ & $\begin{array}{c}0.023 \\
(0.035)\end{array}$ & $\begin{array}{c}0.024 \\
(0.036)\end{array}$ & $\begin{array}{c}-0.008 \\
(0.030)\end{array}$ & $\begin{array}{l}-0.005 \\
(0.030)\end{array}$ \\
\hline Non-parametric & $\begin{array}{c}0.001 \\
(0.025)\end{array}$ & & $\begin{array}{c}0.009 \\
(0.037)\end{array}$ & & $\begin{array}{c}-0.009 \\
(0.034)\end{array}$ & \\
\hline No of. Obs. & 4829 & 4763 & 2463 & 2424 & 2366 & 2339 \\
\hline \multicolumn{7}{|c|}{ Days of marijuana use } \\
\hline Parametric & $\begin{array}{c}0.137 \\
(0.404)\end{array}$ & $\begin{array}{c}0.191 \\
(0.404)\end{array}$ & $\begin{array}{c}0.008 \\
(0.731)\end{array}$ & $\begin{array}{c}0.009 \\
(0.741)\end{array}$ & $\begin{array}{c}0.343 \\
(0.399)\end{array}$ & $\begin{array}{c}0.325 \\
(0.388)\end{array}$ \\
\hline Non-parametric & $\begin{array}{c}0.174 \\
(0.429)\end{array}$ & & $\begin{array}{c}0.097 \\
(0.773)\end{array}$ & & $\begin{array}{c}0.402 \\
(0.384)\end{array}$ & \\
\hline No of. Obs. & 4829 & 4763 & 2463 & 2424 & 2366 & 2339 \\
\hline \multicolumn{7}{|c|}{ Used marijuana more than 10 days } \\
\hline Parametric & $\begin{array}{c}0.010 \\
(0.017)\end{array}$ & $\begin{array}{c}0.012 \\
(0.017)\end{array}$ & $\begin{array}{c}0.003 \\
(0.029)\end{array}$ & $\begin{array}{c}0.004 \\
(0.029)\end{array}$ & $\begin{array}{c}0.019 \\
(0.019)\end{array}$ & $\begin{array}{c}0.018 \\
(0.018)\end{array}$ \\
\hline Non-parametric & $\begin{array}{c}0.015 \\
(0.018)\end{array}$ & & $\begin{array}{c}0.023 \\
(0.019)\end{array}$ & & $\begin{array}{c}0.013 \\
(0.030)\end{array}$ & \\
\hline No of. Obs. & 4829 & 4763 & 2463 & 2424 & 2366 & 2339 \\
\hline Controls & No & Yes & No & Yes & No & Yes \\
\hline
\end{tabular}

Notes: An age bandwidth of 360 days on both sides of the cutoff point of the $19^{\text {th }}$ birthday is used in all models. Standard errors are clustered by the forcing variable and reported in parenthesis. 
Figure 1. The change in selected control variables at the $19^{\text {th }}$ birthday

A. $\log ($ Income $)$

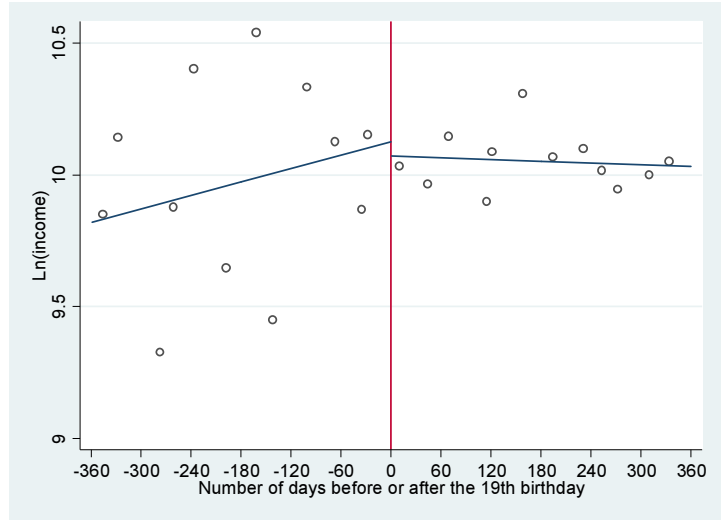

C. Family size

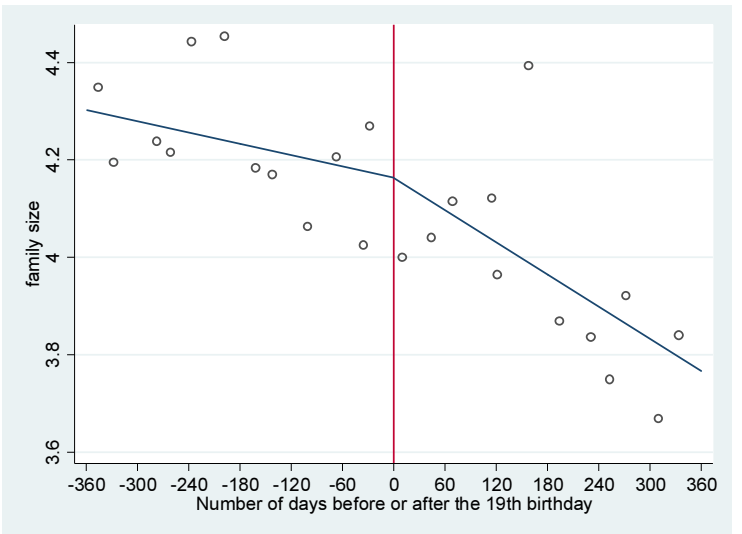

E. Employed

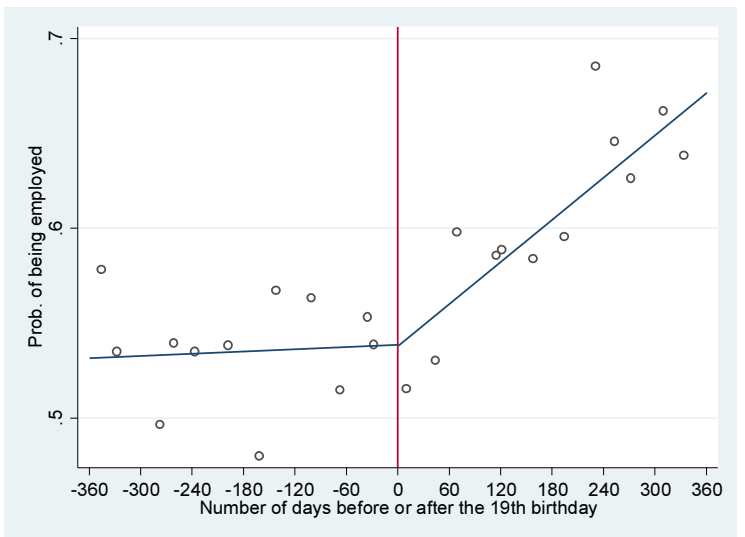

B. Married

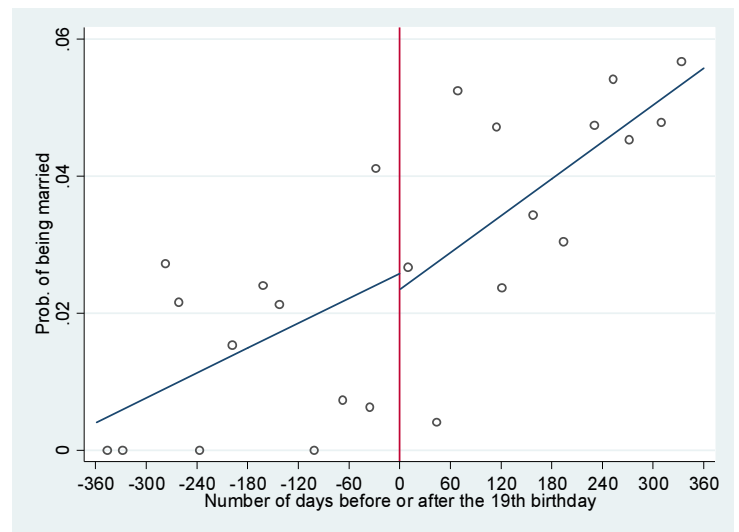

D. Student

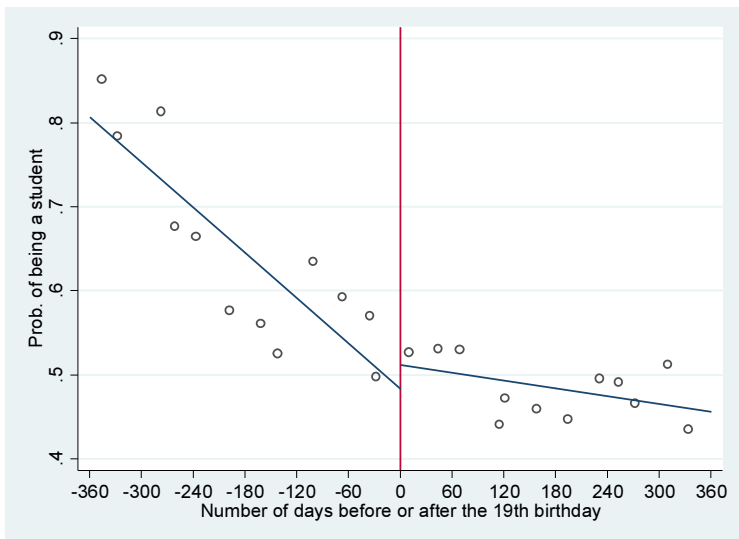

F. Female

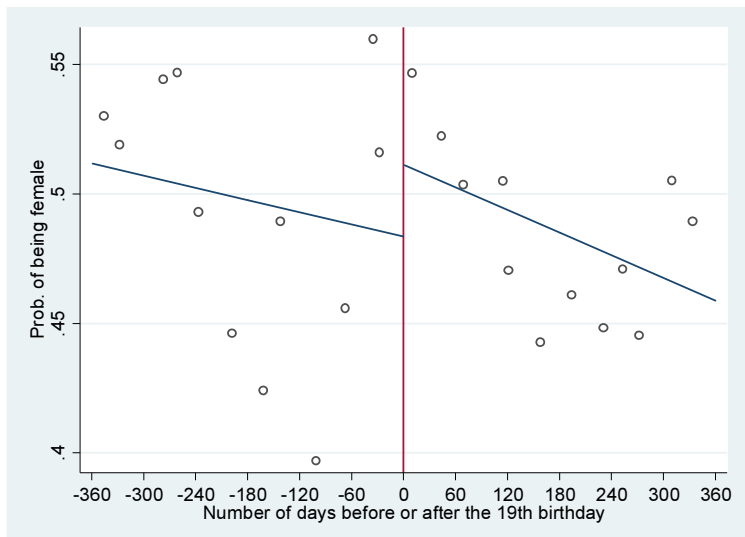

Notes: Mean of the outcome variables for 30 day intervals are plotted. The solid lines are a first-order polynomial fitted on individual observations on both sides of the age-19 cutoff as reported in Table 2 . 
Figure 2. The change in insurance coverage at the $19^{\text {th }}$ birthday

A. Full sample

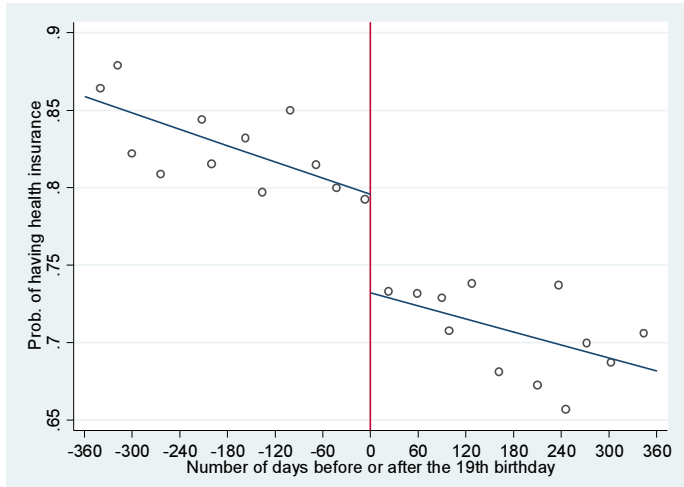

B. Males

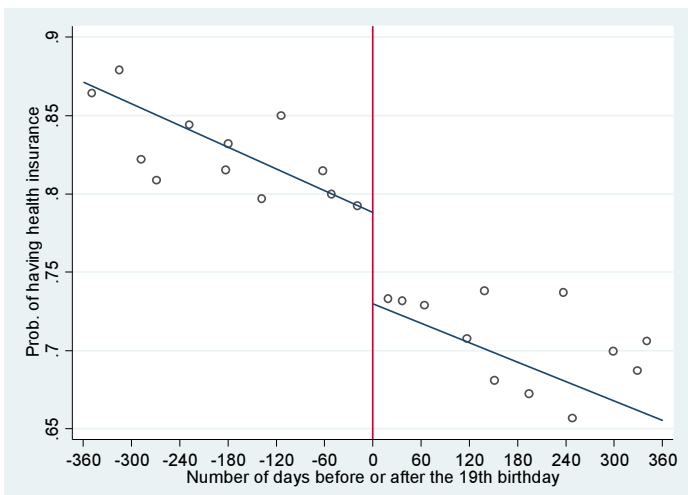

C. Females

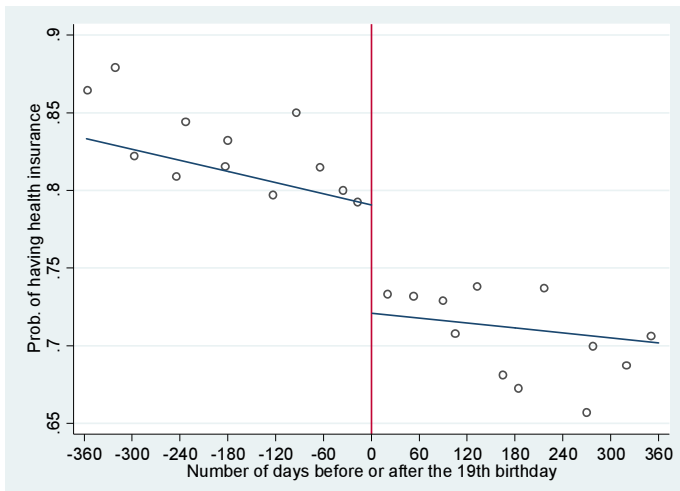

Notes: Mean of the outcome variables for 30 day intervals are plotted. The solid lines are a first-order polynomial fitted on individual observations on both sides of the age-19 cutoff as reported in columns 1, 3, and 5 of Table 3. 
Figure 3 . The change in alcohol consumption at the $19^{\text {th }}$ birthday

A. Average alcohol consumption

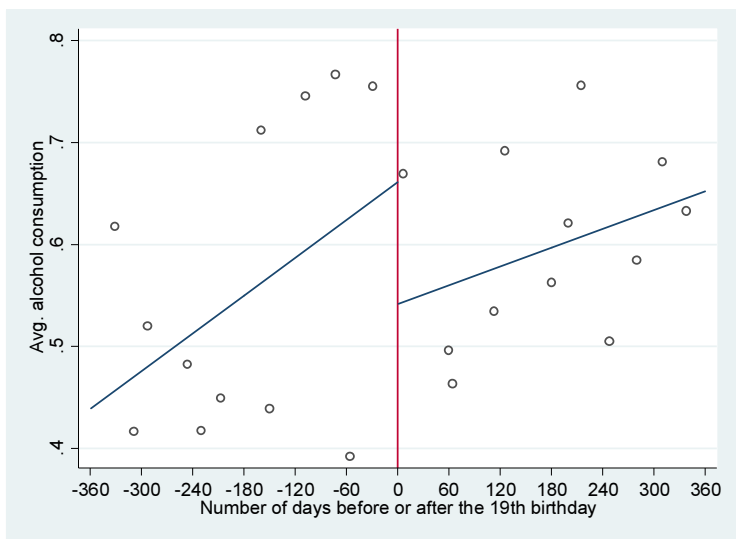

C. Engaged in binge drinking

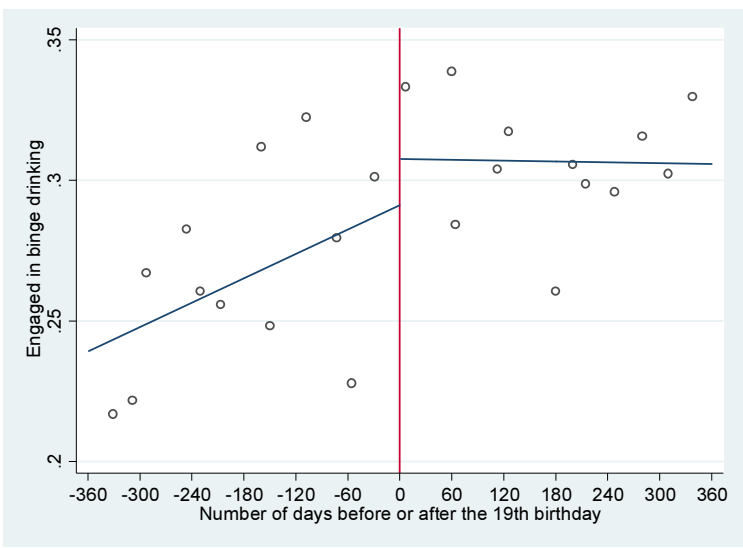

E. Engaged in heavy drinking

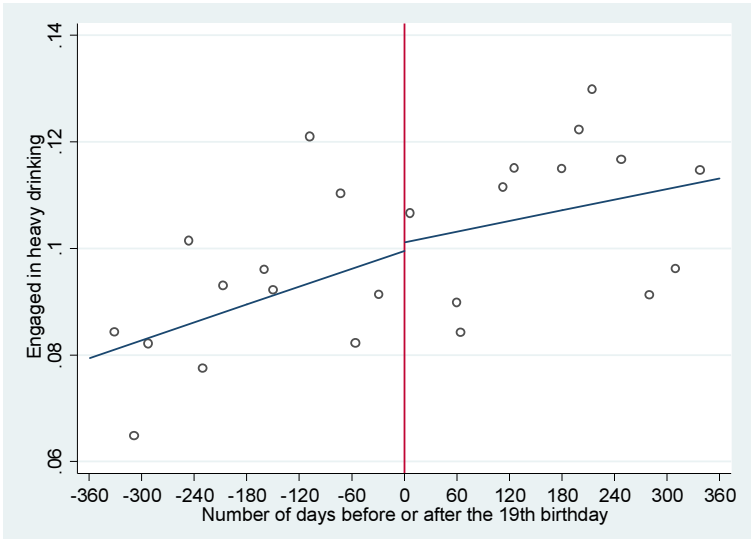

B. Days of alcohol consumption

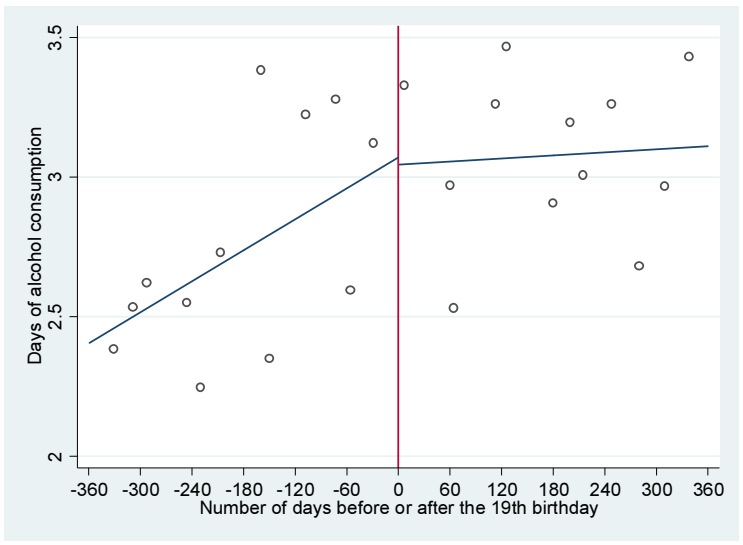

D. Days of binge drinking

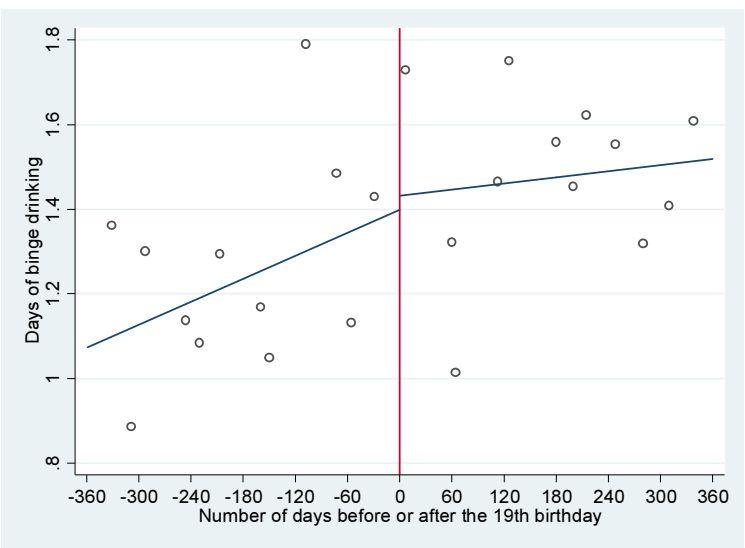

F. Consumed 5 or more drinks

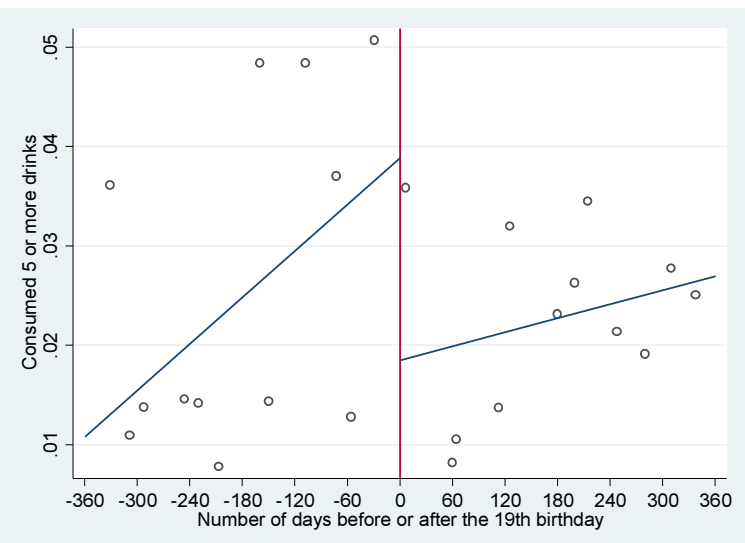

Notes: Mean of the outcome variables for 30 day intervals are plotted. The solid lines are a first-order polynomial fitted on individual observations on both sides of the age-19 cutoff as reported in the first column of Table 5 . 
Figure 4 . The change in smoking behavior at the $19^{\text {th }}$ birthday

A. Days of smoking

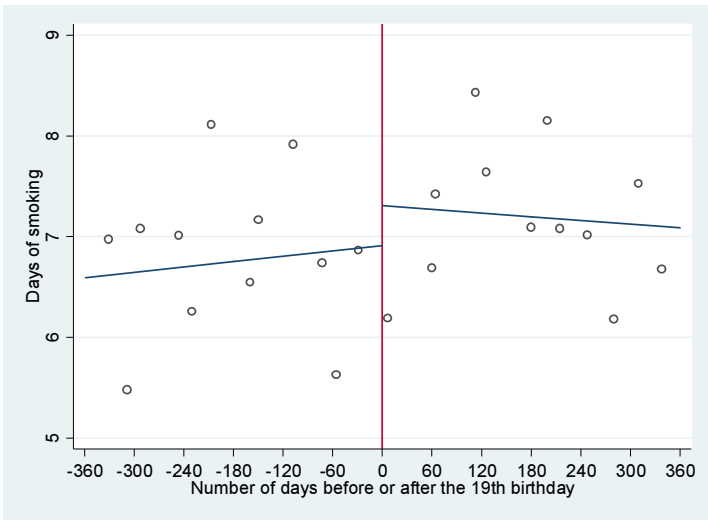

C. Avg. no. of cigarettes smoked

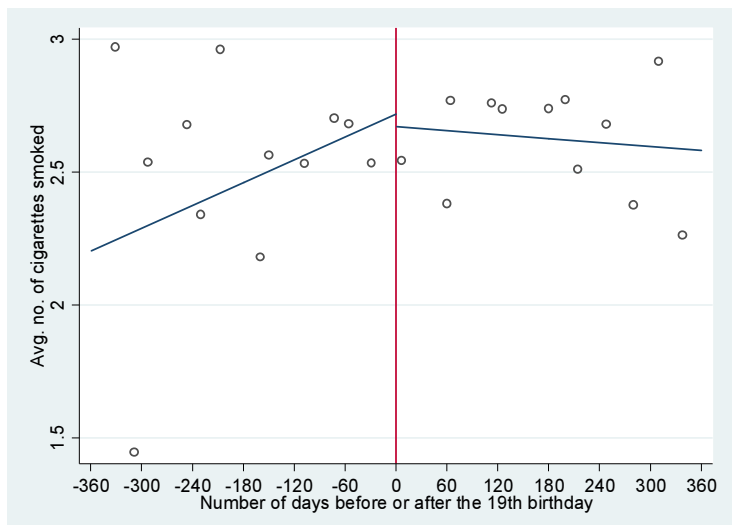

B. Engaged in heavy smoking

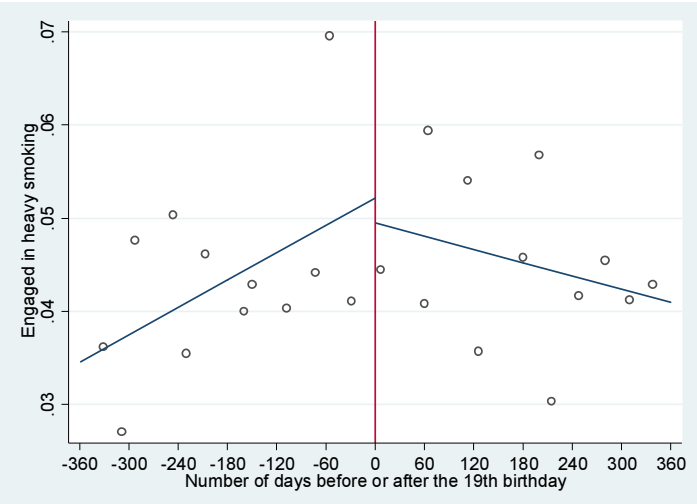

D. Days of heavy smoking

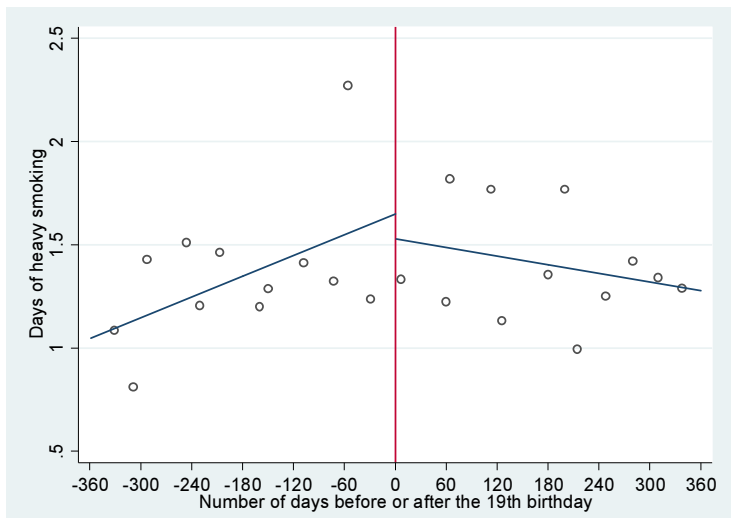

Notes: Mean of the outcome variables for 30 day intervals are plotted. The solid lines are a first-order polynomial fitted on individual observations on both sides of the age-19 cutoff as reported in the first column of Table 6 . 
Figure 5 . The change in marijuana use at the $19^{\text {th }}$ birthday

A. Used marijuana

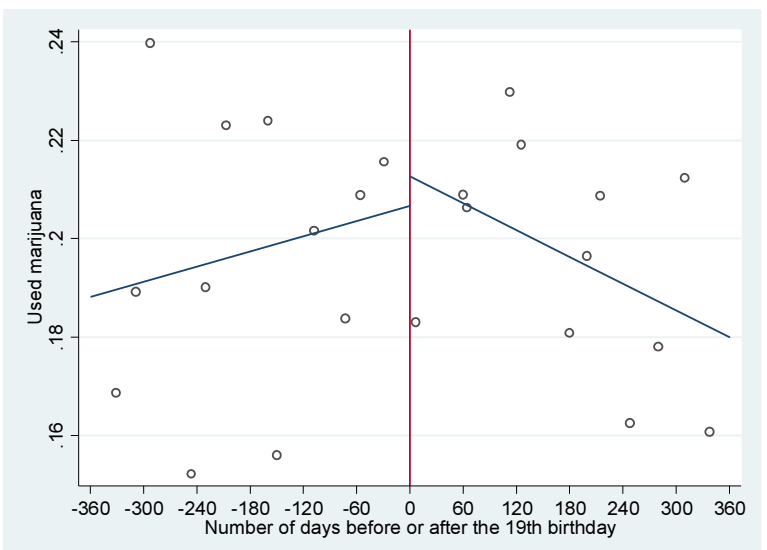

C. Used marijuana more than 10 days

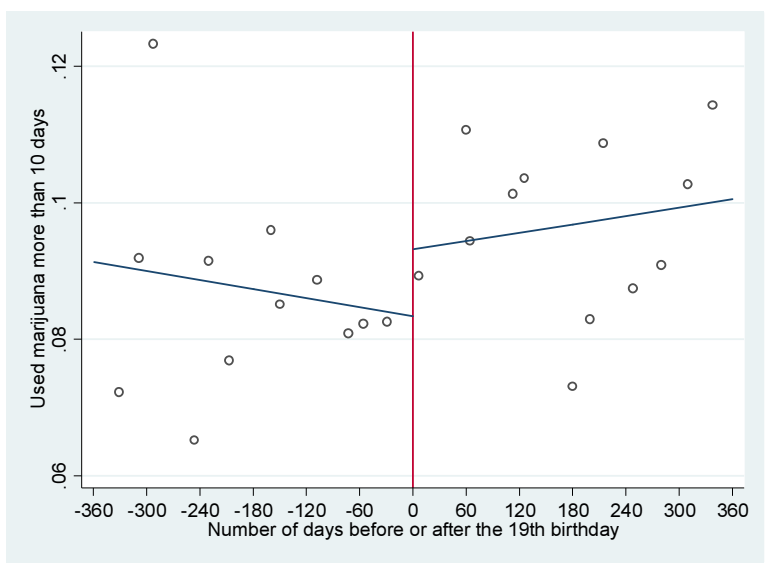

B. Days of marijuana use

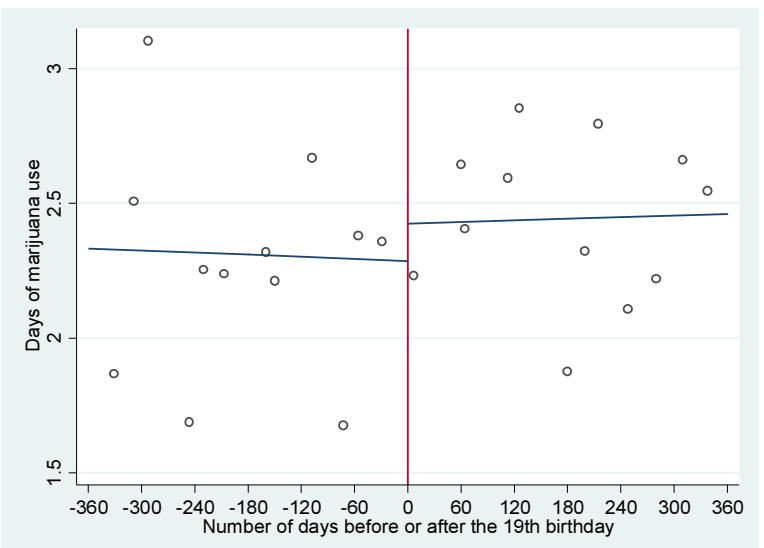

Notes: Mean of the outcome variables for 30 day intervals are plotted. The solid lines are a first-order polynomial fitted on individual observations on both sides of the age-19 cutoff as reported in the first column of Table 7 . 
Appendix A. Description and summary statistics of outcome variables

\begin{tabular}{|c|c|c|c|c|}
\hline & Definition & No. of obs. & Mean & S.D. \\
\hline Insurance & $\begin{array}{l}=1 \text { if the respondent has any kind of health care coverage, } \\
\text { including health insurance, prepaid plans such as HMOs, or } \\
\text { government plans such as Medicare, and }=0 \text { otherwise. }\end{array}$ & 4819 & 0.762 & 0.426 \\
\hline Average alcohol consumption & $\begin{array}{l}\text { Average number of drinks consumed by the respondent per } \\
\text { day in the last } 30 \text { days. }\end{array}$ & 4813 & 0.665 & 1.652 \\
\hline Days of alcohol consumption & $\begin{array}{l}\text { Number of days that the respondent consumed alcohol in the } \\
\text { last } 30 \text { days. }\end{array}$ & 4855 & 3.295 & 5.403 \\
\hline Engaged in binge drinking & $\begin{array}{l}=1 \text { if the respondent consumed five or more drinks in a } \\
\text { single occasion in the last } 30 \text { days, and }=0 \text { otherwise. }\end{array}$ & 4852 & 0.327 & 0.469 \\
\hline Days of binge drinking & $\begin{array}{l}\text { Number of days that the respondent consumed five or more } \\
\text { drinks in a single occasion in the last } 30 \text { days. }\end{array}$ & 4852 & 1.612 & 3.800 \\
\hline Engaged in heavy drinking & $\begin{array}{l}=1 \text { ift the respondent engaged in heavy drinking in the last } \\
30 \text { days, and }=0 \text { otherwise. }\end{array}$ & 4852 & 0.119 & 0.323 \\
\hline Consumed 5 or more drinks on average & $\begin{array}{l}=1 \text { if the respondent on average consumes at least } 5 \text { drinks } \\
\text { a day, and } 0 \text { otherwise. }\end{array}$ & 4813 & 0.027 & 0.162 \\
\hline Used marijuana & $\begin{array}{l}=1 \text { if the respondent used marijuana in the last } 30 \text { days, and } \\
0 \text { otherwise. }\end{array}$ & 4851 & 0.213 & 0.409 \\
\hline Days of marijuana use & $\begin{array}{l}\text { Number of days that the respondent used marijuana in the } \\
\text { last } 30 \text { days. }\end{array}$ & 4851 & 2.602 & 7.215 \\
\hline Used marijuana more than 10 days & $\begin{array}{l}=1 \text { if the respondent used marijuana more than } 10 \text { days in } \\
\text { the last } 30 \text { days. }\end{array}$ & 4851 & 0.102 & 0.303 \\
\hline Days of smoking & $\begin{array}{l}\text { Number of days that the respondent smoked cigarettes in } \\
\text { the last } 30 \text { days. }\end{array}$ & 4859 & 8.006 & 12.477 \\
\hline Engaged in heavy smoking & $\begin{array}{l}=1 \text { if the respondent on average smokes at least } 20 \\
\text { cigarettes a day, and }=0 \text { otherwise. }\end{array}$ & 4857 & 0.056 & 0.229 \\
\hline Avg. no. of cigarettes smoked & $\begin{array}{l}\text { Average number of cigarettes smoked by the respondent per } \\
\text { day in the last } 30 \text { days. }\end{array}$ & 4857 & 3.064 & 7.011 \\
\hline Days of heavy smoking & $\begin{array}{l}\text { Number of days that respondent smoked more than } 20 \\
\text { cigarettes in the last } 30 \text { days. }\end{array}$ & 4859 & 1.714 & 6.931 \\
\hline
\end{tabular}

Notes: Sample weighted means are reported. S.D.: standard deviation. 
Appendix B. Number of observations for each 30-day period before and after the $19^{\text {th }}$ birthday

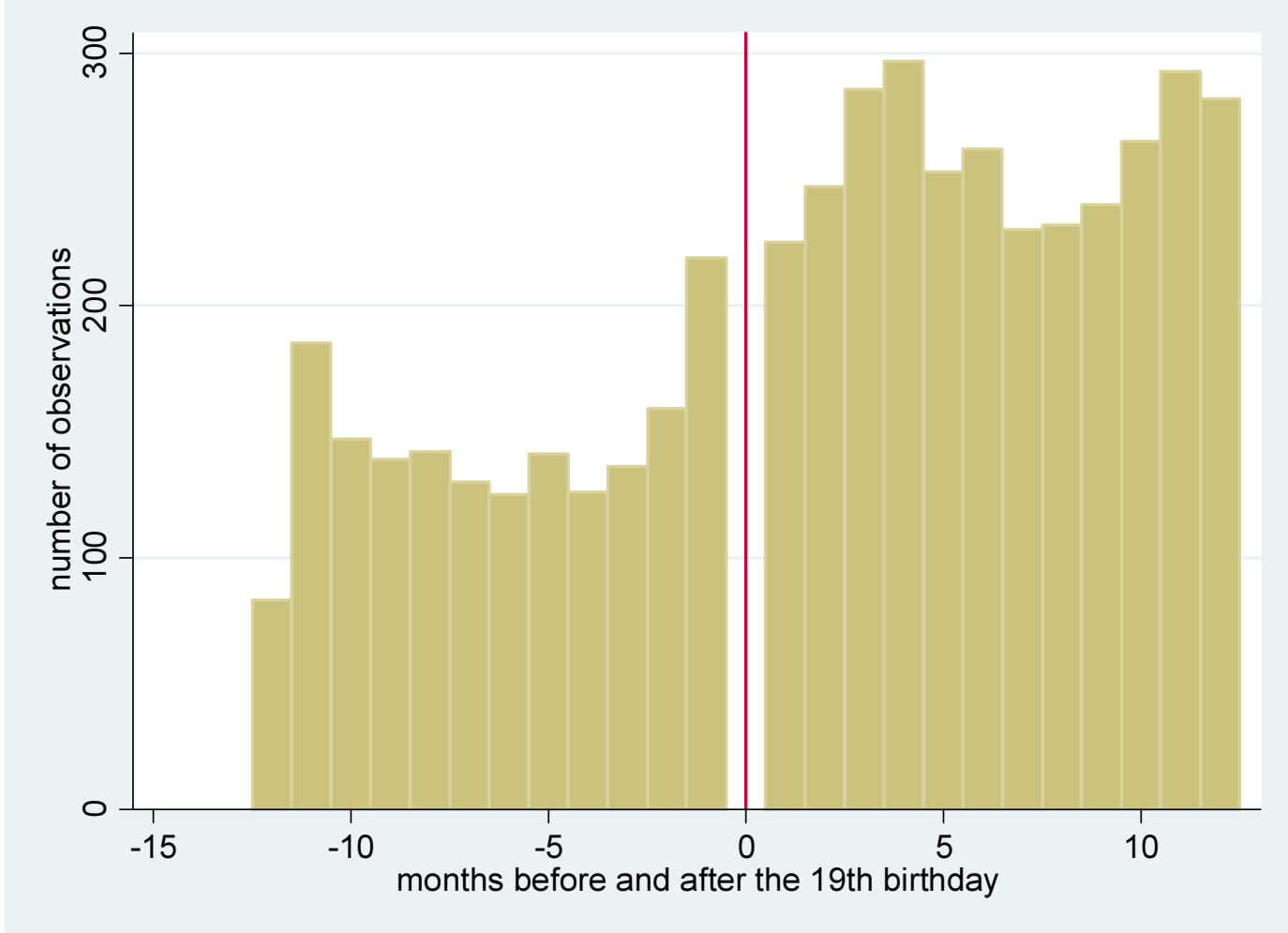

